\title{
Impact of climate changes on the diurnal behaviour of some passerines in some selected habitats of central Punjab, Pakistan
}

\author{
Muhammad Yasin ${ }^{1}$, Hammad Ahmad Khan ${ }^{1, *}$, Sajid Abdullah ${ }^{1}$ and Mansoor Hameed ${ }^{2}$ \\ ${ }^{1}$ Department of Zoology, Wildlife and Fisheries, University of Agriculture, Faisalabad, Pakistan \\ ${ }^{2}$ Department of Botany, University of Agriculture, Faisalabad, Pakistan \\ *Corresponding author's e-mail: druafhammad@yahoo.com
}

\begin{abstract}
Present paper provides information on the impact of climate changes on diurnal rhythms of the four passerines viz, house sparrow (Passer domesticus Linn.), rosy starling (Pastor roseus Linn.), tree swallows (Tachycineta bicolor Hirun.), and brown shrike (Lanius cristatus Linn.) for two years period in the four major agricultural habitats viz. Faisalabad, Sheikhupura, Toba Tek Singh and Khanewal of Central Punjab, Pakistan. Effects of climate catastrophe have been seriously recognized as important inhibitory factors for birds' sustainable existence and conservation. Among the four habitats, present within 120 kilometre radius from Faisalabad district, observations were conducted weekly on active and passive foraging, and the roost exits and returns throughout the day. Weather changes viz. temperature, precipitation and relative humidity were critically recorded. Impacts of temperature were significant and resulted in decline of the active foraging for the four designated birds $(\beta=-2.36,-1.93,-2.15$ and -1.64$)$ whereas, precipitation due to its lowered frequency, exerted negative influence on the house sparrow and brown shrike, but was non-significant for rosy starling and tree swallows. Overall, temperature and relative humidity $(\mathrm{RH})$ were the foremost climate factors and largely reduced the foraging and roosting movements of the four passerine birds'. Nonetheless, effects of lowered rainfall for the four habitats throughout this study were non-significant.
\end{abstract}

Keywords: Climate, ecosystems, vulnerability, birds, Punjab.

\section{INTRODUCTION}

Climate changes lately are considered serious threats to various birds (Parmesan and Yohe, 2003; Parmesan, 2006; Ridchuk et al., 2019). Continuous human activities for several decades have altered the existing climate which have resulted increase of earth temperature $\left(0.85^{\circ} \mathrm{C}\right)$, rise of sea level $(0.23 \mathrm{~m})$ and the melting of ice-glaciers (IPCC, 2007; 2013). Undeniably, such changes in temperature have also seriously jeopardized the global biodiversity influenced by the environmental stressors (Marzluffet al., 2001; Walther et al., 2002; Thomas et al., 2004; Pereira et al., 2010). Environmental fluctuations are highly unpredictable and, therefore, cause undesirable shifts in the faunal populations (IPCC, 2001; Huntley et al., 2006; O'Mahony, 2015).

Several migratory birds seem to have increase their arrival at the suitable roosting sites in winter and also in summer for better foraging, roosting and nesting opportunities (Gienapp et al., 2007; Pearce-Higgins et al., 2019) to accelerate and adjust their breeding schedules. Accordingly, incidence of decline in their population owes to the occurring climate changes (Moller et al., 2008; Salido et al., 2012). Bird roosting worldwide enables large self-sacrifice to expand the competition for the existing resources (Suzuki and Akiyama, 2008; Conklin and Colwell, 2008). Apparently, adaptive values and fitness for majority of birds depend largely on intra-specific competition (Marzluff et al., 1996; Wright et al., 2003) and that of the predatory impacts (Rabenold, 1987; Krause and Ruxton, 2002; Rogers et al., 2006).

Climate is, therefore, considered as the major driver to alter behavioral performance among birds leading to changes in phenology, roost characteristics and the both intrinsic and extrinsic factors. Thus, there occurs direct effect on their physiological adaptations (Crick, 2004). Weather fluctuations are largely unpredictable and cause undesirable changes to the shifts in the bird populations (Huntley et al., 2006; O'Mahony, 2015). Therefore, such variations are assumed to be serious threats to biodiversity of birds and other animals (Gilliland, 2019). Anthropogenic factors and ecosystems vulnerabilities have also reported on serious changes in the decline of useful animal populations (Root et al., 2003; Menzel, 2006; Valladares et al., 2007; Ockendon et al., 2014). According to (Reif and Vermouzek, 2019), several farmland birds have also suffered mortalities in wake of weather

Yasin M., H.A. Khan, S. Abdullah and M. Hameed. 2021. Climate changes on diurnal behaviour. Pak. J. Agri. Sci. 58: 1177-1184. [Received 12 Jan 2021; Accepted 26 Jul 2021; Published (online) 21 Sep 2021] 
variations and not only the deforestation was major ecological predicament to deprive them of food and roosting, but direct effects of high temperature, precipitation and habitat fragmentation are also destructive (Szabo et al., 2012; Bellard et al., 2012; Birdlife international, 2015; Amano, 2020).

Bird movements are inhibited (Moller and Fiddler, 2010) for their space and time orientation (Robinson et al., 2010). Whereas, predictable effects can be recorded on the seasonal movements for their consecutive and non-consecutive migratory shifts (Bauer and Hoye, 2014), unpredictable schedules occur owing to the weather changes. The behaviour of house sparrow (Passer domesticus) in the rural and urban habitations was largely considered communal in nature; however, lately climate modifications caused nonconsecutive shifts to (82\%) in the city avenues, and only $(18 \%)$ in the rural habitats, with $(15 \%)$ global decline in its existing population (Robinson et al., 2005; Birdlife International, 2004; Eaton et al., 2008). According to (Shaw et al., 2008) some risk in ecological conditions and also due to weather fluctuations the sparrows have not only been deprived of their sustainable roosts but severely impacted foraging periodicities in Europe (Chamberlain et al., 2007; Brichetti et al., 2008; Murgui, 2009).

The rosy starling (Pastor roseus), mainly regarded migratory bird of Europe, seems fairly well adapted in the Asian continent finding suitable ecological conditions and serving as bio-indicator of climate change having widespread population (Ali, 2018). The starling has indicated better ecological adaptations and fitness in varied environments (Clarke et al., 1993; Yoder et al., 2004) for its territorial roosting. Some individual bird fitness can occur in certain environments based on its instinct and sensitivity to combat climate fluctuations (Minderman et al., 2010). Recent impacts of high temperatures, precipitation and that of relative humidity have strongly affected the starling also and caused shifts in its behaviour profiles (Ali et al., 1987; Roberts, 1991; Fiedler, 2003; Dunn, 2004; Firrgens et al., 2013).Several birds seem to respond I three possible mechanisms; a. to track the ongoing climatic changes and disperse in different geographical zones for finding suitable weather conditions, $b$. to indicate some adaptations to the prevalent ecological conditions, and c. to feel unfit in the environment to either extinct or perish(Quintero and Weins, 2013). Thus, majority of the avi-fauna presently is stressed by either increase of temperature and also of the other correlated factors leading to their population decline (McCarty, 2001; Mc Laughlin et al., 2002; Hansen et al., 2006). Perhaps, some birds possess the ability to adjust themselves accordingly to the continued climate changes and with the decreased costs and benefits (Vickers et al., 2011). The region of Central Punjab is considered as main agricultural landscape of Pakistan. As such, it contributes $(30 \%)$ of the overall agricultural requirements (Ahmad et al., 2013; Agriculture Pakistan, 2015). The gross domestic products (GDP) of Pakistan largely contribute to agriculture with (42\%) income resources provided to the rural habitats and local farmers (GOP, 2019). Therefore, the agriculture remains complex and based on improved technologies to furnish better incentives to the farmers (Iftikhar et al., 2019). Occurrence of the canal irrigation system (CIS) is highly well developed throughout Asia which came of age in (1947). Three main irrigation canals viz. Jhang, Gogera and rakh are inter-linked with various water tributaries to water the multiple cropping systems (MCS). Predominantly, the sufficiently large canalrest houses (CRHs) comprise 12.5 hectares and were established by the British before the partition of Indo-Pak subcontinent to facilitate farmers. Nonetheless, variety of cultivation offered suitable foraging to the vertebrate pests here, which over the years increased gradually and, this, acquired the status of noxious pests (Taber et al., 1967). Objectives of this study were, therefore, concerned with assessing three climate variables viz. temperature, precipitation and relative humidity to influence the behaviour profiles of the four passerine birds' in the four major habitats of Central Punjab, Pakistan.

\section{MATERIALS AND METHODS}

Present observations regarding assessment of climate changes on four passerine birds' house sparrow (Passer domesticus Linn.), rosy starling (Pastor roseus Linn.), tree swallows (Tachycineta bicolor Hir.) and brown shrike (Lanius cristatus Linn.) were extended for two years viz. October, 2017 till September, 2019 in the four major habitats of Central Punjab (Pakistan) viz. Faisalabad, Toba Tek Singh, Sheikhupura and Khanewal.

Study sites: Climate of Faisalabad $\left(31.45^{\circ} \mathrm{N}\right.$ and $\left.73.13^{\circ} \mathrm{E}\right)$ remains dry hot to humid hot in summer, while cold winters and moderate during spring and fall seasons (Khattak and Khalil, 2015).

Experimental birds: A total of four passerine birds' viz. house sparrow (Passer domesticus) rosy starling (Pastor roseus) tree swallow (Tachycineta bicolor) and brown shrike (Lanius cristatus) were consecutively observed to ascertain their behavior profiles as influenced by climate variations in the four Central Punjab districts, Faisalabad, Toba Tek Singh and Khanewal located in $120 \mathrm{~km}$ radius from Faisalabad.

Methods: Studies were conducted for two years (October 2017 through September, 2019) in all the four districts. All the habitats were well vegetated and predominant seasonal cops were present. Observations on weather modalities viz. temperature, precipitation and relative humidity were recorded in all the designated sites of the four districts of Central Punjab. Weekly observations were recorded regarding the day-long active and passive foraging and the roost exits and returns in morning and evening durations. Apparently, of the four birds', non-consecutive (short) and 
consecutive (long) bird shifts were evident from their original roosts.

Bird counts: Numbers of the four passerine birds were critically assessed and numerically counted as impacted. Observations were compared relative to the three climate variables throughout the day with 30 minutes intervals. Such time durations were constant throughout the studies for maintenance of time-scale uniformity for the bird counts throughout the days. Use of digital weather station (WS-2320 CE-MISOL), was incorporated in all observations to determine the variabilities for temperature, precipitations and relative humidity.

Statistical analysis: The collated data of present study was statistically analyzed using the design Generalized Linear Mixed Model (GLMM).

\section{RESULTS}

Active foraging: Foraging is regarded important to the bird existence. It was evident that, influence of temperature, precipitation and relative humidity on the dynamic foraging of the four passerines remained robust $\left(\mathrm{P}=0.002 * *, 0.0015^{* *}\right.$, $0.004 * *$ and $0.0017 * *)$ respectively whereas, low incidence of rainfall was nearly non-significant. Nonetheless, effects of relative humidity $(\mathrm{Rh})$ were significant to the house sparrow and also to rosy starling. However, their impacts were negligible for the brown shrike and tree swallows (Table 1). Application of the GLMM model, therefore, apparently indicated that with the single degree increase in temperature $\left({ }^{\circ} \mathrm{C}\right)$, there was decline in foraging for 2.36 P. domesticus, 1.93 P. roseus, $2.15 T$. bicolor and 1.64 L. cristatus(Figures 1, 2, 3).

Passive foraging: Passive foraging (PF) as depicted by the GLMM indicated that of the three main climate drivers, temperature did not seem to exert significant effects for all the four passerines in all habitats $(\mathrm{P}=0.069 ; 0.084 ; 0.0 .69 ; 0.07)$, and similarly, impact of little rainfall also remained negligible. Effects of relative humidity $(\mathrm{Rh})$ were also nonsignificant and evinced that, passive foraging profiles which had occurred due to strong effects of temperature lately, invariably were non-consequential for the four birds (Figures $4,5,6)$.

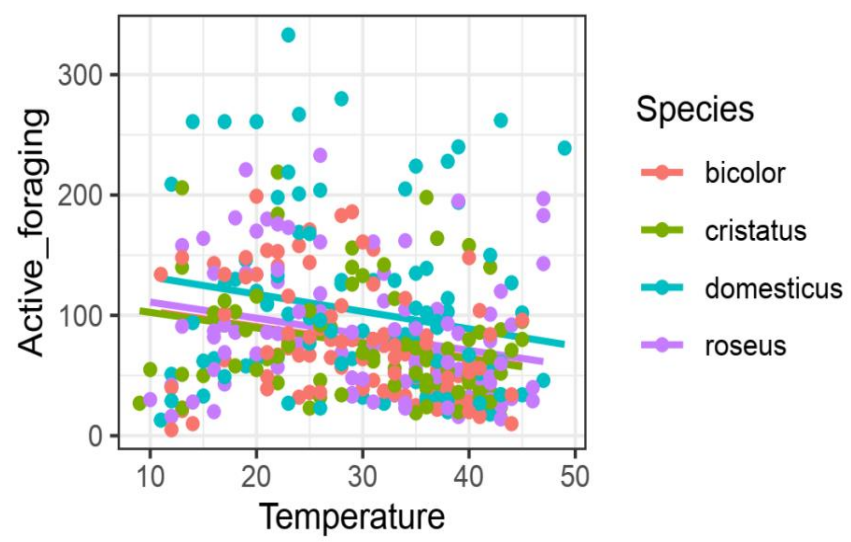

Figure 1. Impact of temperature on foraging of four bird species.

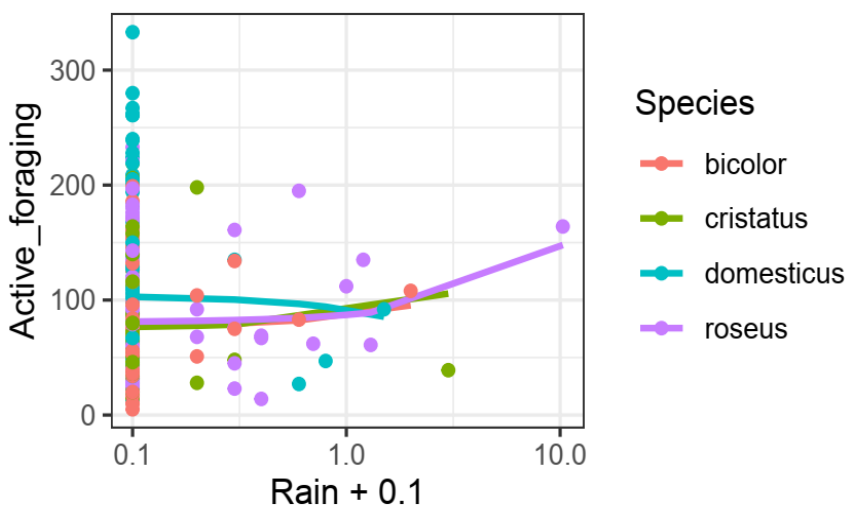

Figure 2. Impact of rainfall as indicated on bird foraging activities.

Table 1. Effects of temperature $\left({ }^{\circ} \mathrm{C}\right)$, relative humidity $(\%)$, and precipitation $(\mathrm{mm})$ recorded on active foraging, of four bird species.

\begin{tabular}{lllcccc}
\hline Bird behaviour & Climate factors & Bird species & Slope $(\boldsymbol{\beta})$ & Standard error & t-value & p-value \\
\hline Active foraging & Temperature & P. domesticus & -2.36 & \pm 0.76 & -3.09 & $0.002^{* *}$ \\
& & P. roseus & -1.93 & \pm 0.59 & -3.28 & $0.001^{* *}$ \\
& & T. bicolor & -2.15 & \pm 0.61 & -3.51 & $0.004^{* *}$ \\
& Precipitation & L. cristatus & -1.64 & \pm 0.50 & -3.25 & $0.002^{* *}$ \\
& & P. domesticus & -7.41 & \pm 42.2 & -0.17 & 0.860 \\
& & P. roseus & 7.43 & \pm 5.14 & 0.150 & 0.45 \\
& Humidity & L. cristatus & -1.14 & \pm 14.28 & -0.08 & 0.940 \\
& & P. domesticus & -1.35 & \pm 0.57 & -2.35 & $0.020^{*}$ \\
& & P. roseus & -0.92 & \pm 0.41 & -2.23 & $0.028^{*}$ \\
& & T. bicolor & -0.38 & \pm 0.39 & -0.98 & 0.320 \\
\hline
\end{tabular}




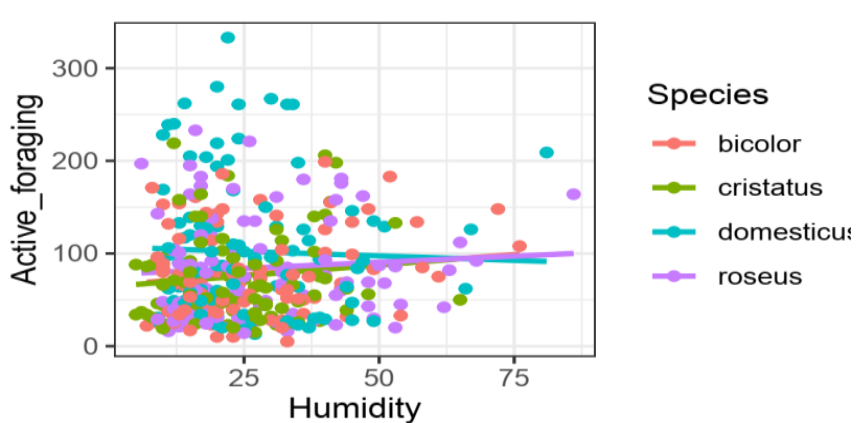

Figure 3. Effects of relative humidity (RH) on active foraging.

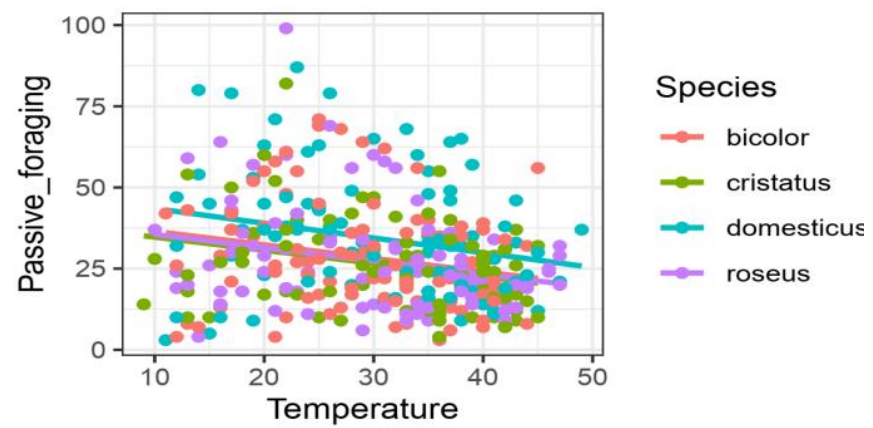

Figure 4. Effect of temperature on passive foraging.

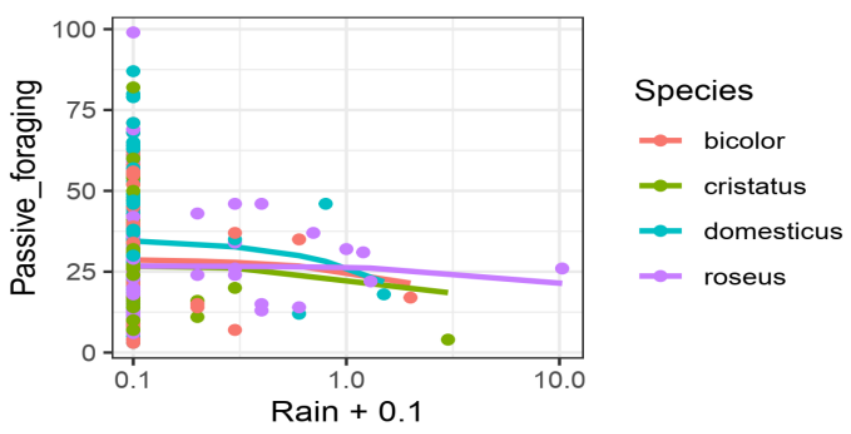

Figure 5. Effect of rain on passive foraging. Precipitation has no significant role in the passive foraging of all four bird species.

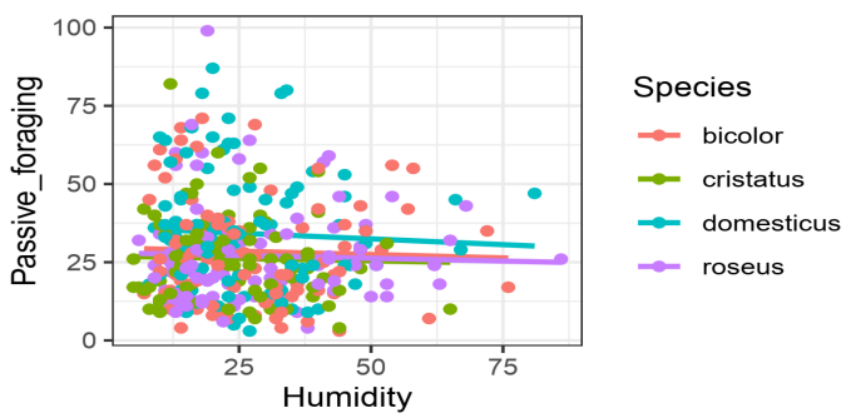

Figure 6. Impacts of humidity on passive foraging. Humidity shows a significant role in passive foraging on three species out of four, except $P$. roseus.
Roosting exits: Roosting behaviour is trivial to all avi-fauna. Predominantly, roosting birds' elicit direct response to any of the altered roosting profiles. In this study, effects of temperature, precipitation and relative humidity for the four designated birds' showed that, temperature yet again was instrumental for their negative slope indicators $(-3.05$ for $P$. domesticus; -2.20 for $P$. roseus; -1.96 for $T$. bicolor and -2.14 for $L$. cristatus). Roost exits were largely reduced owing to elevated temperature for all the passerine birds. Thus, according to the GLMM, increase of each degree temperature, reduced their roost leaving percentage as (for the sparrow 3.05 ; for the rosy starling 2.20; tree swallow 1.96 and similarly for the brown shrike, 2.14). Nonetheless, due to low precipitation percentage, there were least significant results except for that of the rosy starling $(+11.56)$ which appeared to augment its roost leaving in pursuit of the abundant insects after the little rain fall. Invariably, a non-significant biological variation of precipitation regarding the three other birds was due to the low rain fall in the designated habitats. Finally, considering the relative humidity (RH) for the four sampled birds, Tachycineta bicolor was strongly impacted $(0.99 \%)$ exits were estimated contrary to the three other birds (Figures $7,8,9)$.

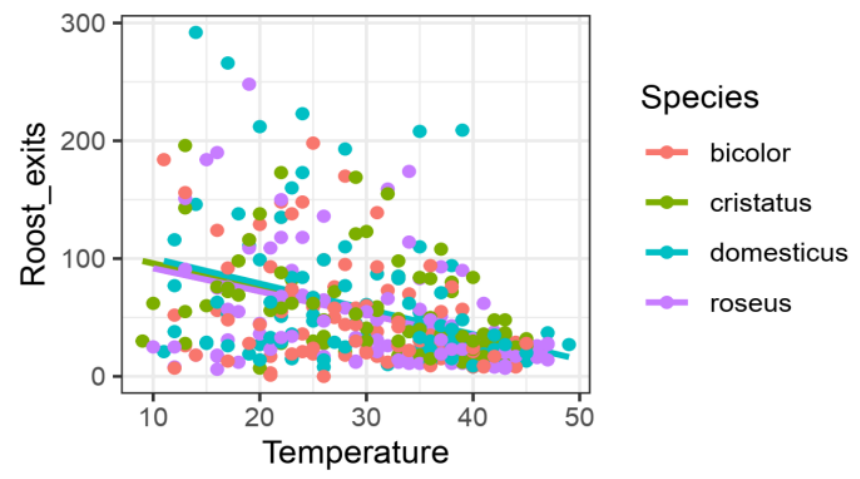

Figure 7. A prominent adverse effect of temperature on Roost exits of almost all four bird species was observed.

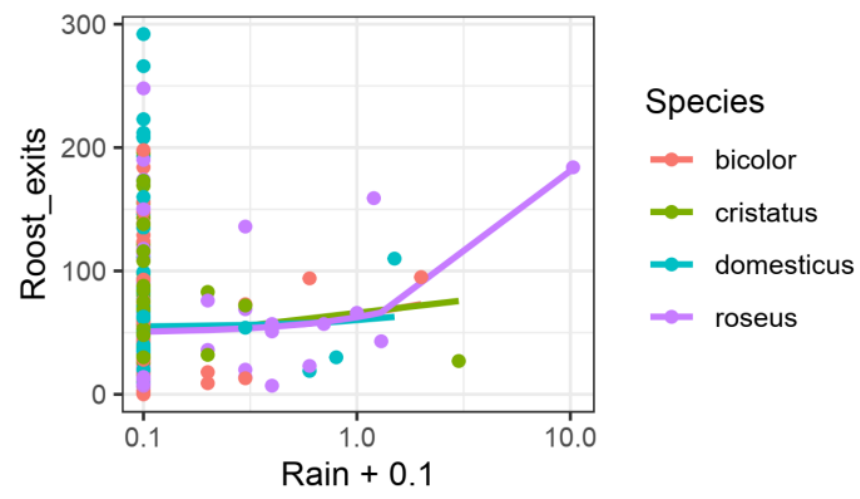

Figure 8. Effect of rain on roost exits indicates strong positive effect on Pastor roseus. 


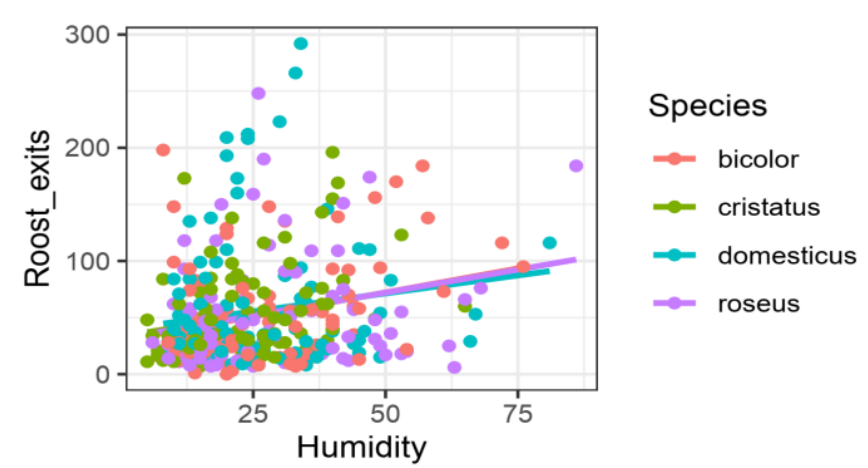

Figure 9. Impact of humidity on the exit of all the four species.

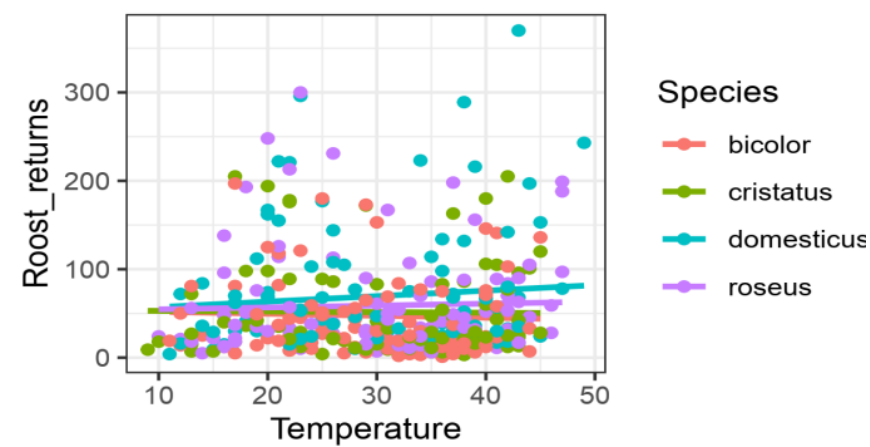

Figure 10. Temperature effects on Roost returns, on the four passerine birds.

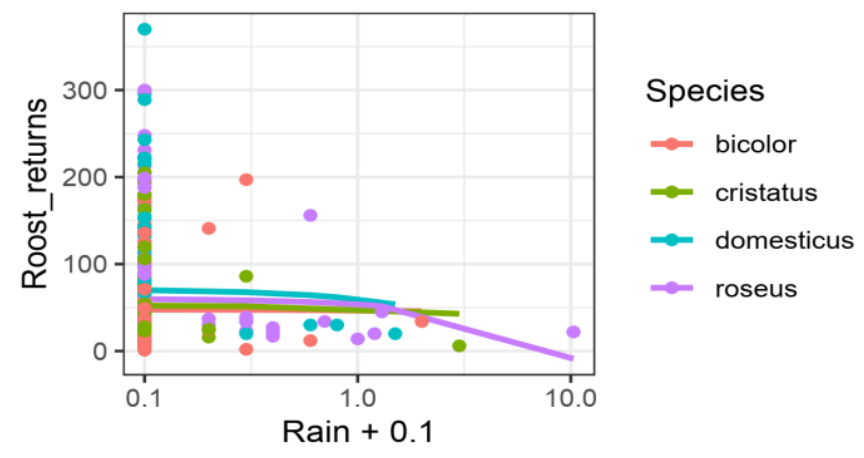

Figure 10.Precipitation impacts on the roost returns of four bird species.

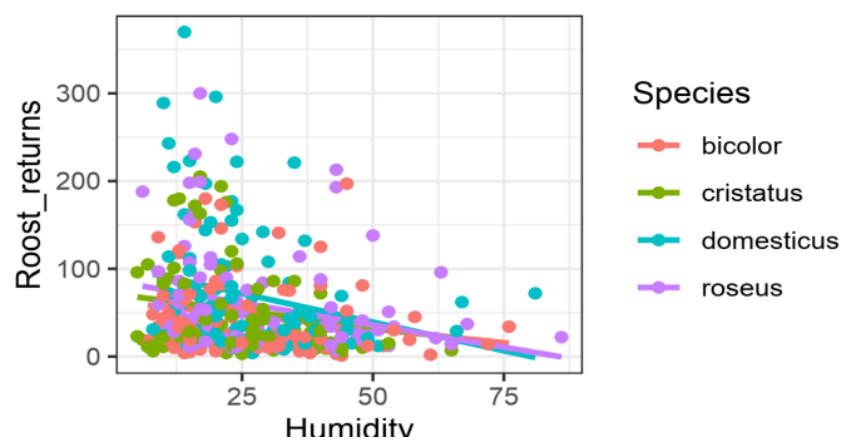

Figure 12. Robust activity of relative humidity in roosting returns of all four birds.
Roost returns: It was apparent that the roost returns figured according to the GLMM Model, temperature and precipitation remained negligible to impact the returns and was, therefore, suitable to it. However, some alterations were ascertained in the elevated relative humidity slope (1.37) for T. bicolor and (2.06) for L. cristatus (Figures 10, 11, 12).

\section{DISCUSSION}

Present study was focused on adjudging the three major weather variables viz. temperature, rainfall and relative humidity regarding behaviour profiles of four passerine birds; Passer domesticus, Pastor roseus, Tachycineta bicolor and Lanius cristatus. All of them occur in throughout the cultivations in Central Punjab with their established roosts. Weekly observations were cautiously conducted to indicate impact of each of three climate factors regarding their diurnal foraging and roost behaviour in the four selected habitats.

Foraging and feeding are important aspects of life-history of all birds' on the daily basis. It was differentiated into two types; active and passive. Initially, it was hypothesized that the impacts of climate variables would diminish the foraging periodicities. Apparently, incidence of higher temperature was concerned as the plausible inhibitory factor for their roosting and foraging activities in all four locations as statistically supported by the Generalised Linear Mixed Model (GLMM). Observations on the passive foraging (PF) did not seem to be significant in reduced foraging efficiencies yet were responsible to shift for short and long duration of the four passerine birds as have also reported by (Lourdais et al., 2014; Killen et al., 2016). Moreover, the micro habitats are considered to be important to dispel certain birds in the increased temperature from their original habitats, and largely drop both the modes of foraging (Brambilla et al., 2016; 2017).

Roosting habits, therefore, remain important to the well-being of the avi-fauna. Some of them are regarded logical ecological considerations for the better survival of birds. Majority of the birds adjust to the required environmental changes to facilitate their endurance. Predictable ecological adjustments become unavoidable to them or they suffer extinctions (Baxter and Fairweather, 1998). Roost exits are highly significant in their day-long activities of not only finding suitable food but also to search for tree depressions or cavities to transform as productive nests. It was evident in present study that the roost periodicities (exits and returns) possessed decreased intensity regarding morning and evening hours, and possibly aversion to high temperature was main inhibitory factor to it. Roost movements as have been reported by (Przybylo et al., 2000) for flycatchers and some more birds were also of reduced efficiencies owing to the higher temperatures. Lately, warm climate also have impairment on the efficiencies in breeding performance by causing it to occur fairly early and, thus, provoke stress (Inouye et al., 2000). 
Roost returns were numerically more than their exits in the morning. It was due to the joining of conspecifics to the already returning four passerines to their respective particular communal roosts. Present findings also reported that the GLMM also provided measure of the occurrence of biological variation among the four passerines with their deviated magnitudes from their existence as also shown by (Seavy et al., 2005).

Impact of precipitation remained nearly negligible throughout the present observations due to moderate rainfall, where as effect of relative humidity $(\mathrm{RH})$ on the foraging of the four sampled birds had negative influence, and as such, house sparrow and the rosy starling suffered serious decline in their foraging efficiencies. Nevertheless, except for the brown shrike showing more reduced activities, rest of three species expressed negligible impacts. The roost exits further depicted somewhat mixed proportions of the relative humidity and the slow exits of the $P$. domesticus and $P$. roseus and L. cristatus. Contrary, significant exits were recorded for the $T$. bicolor. Concurrently, as predicted with the GLMM, relative humidity exerted important impact to inhibit the returns of the four passerines in their specific roosts in the evening (Table.1; Figures.1-12). Similar studies by (Okpara et al., 2016) regarding effect of relative humidity on hens in a humid tropical climate also support the present work.

Conclusions: Four passerines are fairly common throughout Central Punjab, but house sparrow with flexible adaptations seemed numerically better. Evidently, all birds' possessed well-established communal roosts for multiple years considering their safety among the old and tall trees. Although weather fluctuations have their impacts on the varied behaviour of birds; it was evinced that temperature was the main driving factor to inhibit efficient foraging activities, while paucity of precipitation could not be regarded to be significant to alter foraging and roosting habits, and relative humidity levied mixed effects on the four passerines in all the habitats. Optimum temperature regarding the active foraging was $25-30^{\circ} \mathrm{C}$ and for passive foraging below $25^{\circ} \mathrm{C}$. Roost exits ranged between $15-20^{\circ} \mathrm{C}$ and it was $45-50^{\circ} \mathrm{C}$ for the roost returns. At $25-45 \%$ relative humidity, roost exits and active foraging were highest for all the four birds.

\section{REFERENCES}

Agric. Pakistan. 2015. Analysis of agricultural subsectors contribution growth rate in agriculture, GDP, Pakistan. Int. J. Econ. Finance. 8:156-161.

Ahmad, K.F.Z., M. Sagheer, M.H. Hassan., H.T. Gul., S.A. Manzoor and A. Wahid. 2013. Agricultural dynamics in Pakistan: current issues and solutions. Russ. J. Agric. Soc.Sci. 8:20-26.

Ali, F., T.A. Khan, A. Alamgir and M.A. Khan. 2018. Climate Change-Induced Conflicts in Pakistan: From National to
Individual Level. Earth Syst. Environ. 2:573-599.

Ali, M.N., S. Sharma and S.S. Brar. 1987.Colonisation in birds:important roosting character for birds. J. Anim. Ecol. 4:44-48.

Amano, T., T. Székely, H.S. Wauchope, B. Sandel, S. Nagy, T. Mundkur, T. Langendoen, D. Blanco, N.L. Michel and W.J. Sutherland. 2020. Responses of global waterbird populations to climate change vary with latitude. Nat. Clim. Chang. 10:959-964.

Bauer, S. and B.J. Hoye. 2014. Migratory animals couple biodiversity and ecosystem functioning worldwide. Science. 344:305-312.

Baxter, G.S. and P.G. Fairweather. 1998. Does available foraging area, location or colony character control the size of multispecies egret colonies? Wildl. Res. 25:23-27.

Bellard, C., C. Bertelsmeier, P. Leadley, W. Thuiller and F. Courchamp. 2012. Impacts of climate change on the future of biodiversity. Ecol. Lett. 15:365-377.

Bird Life International. 2004 Threatened birds of the world. Bird Life International (http://www.birdlife.org/datazone/species/index.html).

Bird Life International.2015. Species fact-sheet: Brachyramphus marmoratus, report p. 117.

Brambilla, M., M. Cortesi, F. Capelli, D. Chamberlain, P. Pedrini and D. Rubolini. 2017. Foraging habitat selection by Alpine White-winged Snowfinches Montifringilla nivalis during the nestling rearing period. J. Ornithol. 158:277-286.

Brambilla, M., P. Pedrini, A. Rolando and D.E. Chamberlain. 2016. Climate change will increase the potential conflict between skiing and high-elevation bird species in the Alps. J. Biogeogr. 43:2299-2309.

Brichetti, P., D. Rubolini, P. Galeotti and M. Fasola. 2008. Recent declines in urban Italian Sparrow Passer (domesticus) italiae populations in northern Italy. Ibis. 150:177-181.

Chamberlain, D.E., M.P. Toms, R. Cleary-McHarg and A.N. Banks. 2007. House sparrow (Passer domesticus) habitat use in urbanized landscapes. J. Ornithol.148:453-462.

Clarke, K.R. 1993. Non-parametric multivariate analyses of changes in community structure. Austral Ecol. 18: 117143.

Conklin, J.R. and M.A. Colwell. 2008. Individual associations in a wintering shorebirdpopulation. J. Field Ornithol.79:332-40.

Crick, H.Q.P. 2004. The impact of climate change on birds. IBIS. 146:48-56.

Dunn, P. 2004. Breeding dates and reproductive performance: Adv. Ecol. Research. 35:69-87.

Eaton, M., Balmer, D., Burton, N., Grice, P., Musgrove, A., Hearn, R., Hilton, G., Leech, D., Noble, D., Ratcliffe, N., Rehfisch, M., Whitehead, S. and Wotton, S. 2008. The State of the UK's Birds. 2008. Sandy, UK: RSPB report pp.23. 
Fiedler, W. 2003. Recent Changes in Migratory Behaviour of Birds: A Compilation of Field Observations and Ringing Data. Avian Migration. Springer Berlin Heidelberg, Berlin, Heidelberg. pp.21-38.

Friggens, M.M., D.M. Finch and K.E. Bagne. 2013. Vulnerability of species to climate change in SouthWest. Auk.12:20-29.

Gienapp, P., R. Leimu and J. Merilä. 2007. Responses to climate change in avian migration time ;microevolution versus phenotypic plasticity. Clim. Res.35:25-35.

Gilland, H.C. 2019. Rising temperature could some US state birds, stateless. Nat. Adubon., Report. pp.20.

GOP, 2019.Pakistan Economic Survey. Importance of agriculture in Pakistan's economy and

Development. Gov. of Pakistan, Fin. Div. pp.287.

Hansen, J., M. Sato, R. Ruedy, K. Lo, D.W. Lea and M. Medina-Elizade. 2006. Global temperature change. Proc. Natl. Acad. Sci. USA. 103:14288-14293.

Harms, K.E. and J.R. Eberhard. 2003. Roosting Behaviour of the Brown-throated Parakeet (Aratinga pertinax) and Roost Locations on Four Southern Caribbean Islands. Ornithol. Neotrop.14:79-89.

Houston, W.A. 2013. Breeding cues in a wetland-dependent Australian passerine of the seasonally wet-dry tropics. Austral. Ecol. 38:617-626.

Huntley, B., Y.C. Collingham, R.E. Green, G.M. Hilton, C. Rahbek and S.G. Willis. 2006. Potential impacts of climatic change upon geographical distributions of birds. IBIS. 148:8-28.

Iftikhar, M., G.A. Khan and J. Hussain. 2019. Identification and prioritization of agricultural risks with special context of rice crop in the Punjab, Pakistan. Int. J. Agric. Ext. 7: 99-105.

Inouye, D.W., B. Barr, K.B. Armitage and B.D. Inouye. 2000. Climate change is affecting altitudinal migrants and hibernating species. Proc. Natl. Acad. Sci. USA, 97: 1630-1633.

IPCC, 2001. Climate Change 2001: The Scientific Basis. Contribution of Working Group I to the Third Assessment Report of the Intergovernmental Panel on Climate Change. Cambridge University Press, Cambridge, UK. pp. 881.

IPCC, 2007. Fourth Assessment Report: Climate Change 2007: The Physical Science Basis. Intergovernmental Panel on Climate Change, Cambridge University Press, Cambridge, UK.

IPCC, 2013: Climate Change: The Physical Science Basis. Working Group I Contribution to the Fifth Assessment Report of the Intergovernmental Panel on Climate Change, Cambridge University Press, Cambridge, United Kingdom and New York, NY, USA 1535.

Krause, J. and G. Ruxton. 2002. Living In Groups.Oxf. Univ.Press Ecol.and Evol. Series, England. pp.798.
Mabb, K.T. 1997. Nesting behaviour of Amazona parrots and Rose-ringed Parakeets in the San Gabriel Valley, California. West. Birds. 28:209-217.

Marzluff, J. M., R. Bowman and R. Donnelly. 2001. Avian ecology and conservation in an urbanizing world. Norwell, MA: Kluwer Acad. Press. pp. 19-23.

Marzluff, J.M., B. Heinrich and C.S. Marzluff. 1996. Raven roosts are mobile information centres. Anim. Behav. 51:89-103.

Mc Laughlin, J.F., J.J. Hellmann, C.L. Boggs and P.R. Ehrlich. 2002. Climate change hastens population extinctions. Proc. Nat. Acad. Sci., USA. 99:7670-7674.

McCarty, J.P. 2001. Variation in Growth of Nestling Tree Swallows across Multiple Temporal and Spatial Scales. Auk.118:176-190.

Menzel, A., T.H. Sparks, N. Estrella, E. Koch, A. Aasa, R. Ahas, K. Alm-Kübler, P. Bissolli, O. Braslavská, A. Briede, F.M. Chmielewski, Z. Crepinsek, Y. Curnel, Å. Dahl, C. Defila, A. Donnelly, Y. Filella, K. Jatczak, F. Måge, A. Mestre, Ø. Nordli, J. Peñuelas, P. Pirinen. 2006. European phenological response to climate change matches the warming pattern. Glob. Chang. Biol. 12:1969-1976.

Mezquida, E.T. and L. Marone. 2003. Comparison of the reproductive biology of two Poospiza warbling-finches of Argentina in wet and dry years. Ardea. 91:251-262.

Minderman, J., J.M. Reid, M. Hughes, M.J.H. Denny, S. Hogg, P.G.H. Evans and M.J. Whittingham. 2010. Novel environment exploration and home range size in starlings Sturnus vulgaris. Behav. Ecol. 21:1321-1329.

Moller, P., W. Fiedler and P. Berthold. 2010. Long-term time series of ornithological data:effects of climate change on birds, report. pp. 37-43.

Murgui, E. 2009. Seasonal patterns of habitat selection of the House Sparrow Passer domesticus in the urban landscape of Valencia (Spain). J. Ornithol. 150:85-94.

O’Mahony, P. 2015. Climate change. Eur. J. Soc. Theory. 18:308-326.

Ockendon, N., D.J. Baker, J.A. Carr, E.C. White, R.E.A. Almond, T. Amano, E. Bertram, R.B. Bradbury, C. Bradley, S.H.M. Butchart, N. Doswald and W. Foden. 2014. Mechanisms underpinning climatic impacts on natural populations: altered species interactions are more important than direct effects. Glob. Chang. Biol. 20:2221-2229.

Okpara, M., C. Egbu and A. Ani. 2016. Effect of relative humidity on the performance of shaver brown hens in a humid tropical environment. Adv. Res.7:1-5.

Parmesan, C. 2006. Ecological and evolutionary responses to recent climate change. Annal. Rev. Ecol. Syst.37:637669.

Parmesan, C. and G. Yohe. 2003. A globally coherent fingerprint of climate change impacts across natural systems. Nature. 421:37-42. 
Pearce-Higgins, J.W., P.J. Lindley, I.G. Johnstone, R.I. Thorpe, D.J.T. Douglas and M.C. Grant. 2019. Sitebased adaptation reduces the negative effects of weather upon a southern range margin Welsh black grouse Tetrao tetrix population that is vulnerable to climate change. Clim. Change. 153:253-265.

Pereira, H.M., P.W. Leadley, V. Proença, R. Alkemade, J.P.W. Scharlemann, J.F. Fernandez-Manjarrés, M.B. Araújo, P. Balvanera, R. Biggs, W.W.L. Cheung, L. Chini, H.D. Cooper, E.L. Gilman and S. Guénette. 2010. Scenarios for global biodiversity in the 21 st century. Sci. 330:1496-1501.

Przybylo, R., B.C. Sheldon and J. Merilä. 2000. Climatic effects on breeding and morphology: Evidence for phenotypic plasticity. J. Anim. Ecol.69:395-403.

Quintero, I. and J.J. Wiens. 2013. Rates of projected climate change dramatically exceed past rates of climatic niche evolution among vertebrate species. Ecol. Lett.16:10951103.

Rabenold, P.P. 1987. Roost Attendance and Aggression in Black Vultures. Auk, 104:647-653.

Reif, J. and Z. Vermouzek. 2019. Collapse of farmland bird populations in an Eastern European country following its EU accession. Conserv. Lett.12: e12585.

Ridchuk, L.N., B.R. walters and B.M. Lofgren. 2019. Climate change causing changes in birds. Int. J. Sci. 3:188-204.

Roberts, T.J., 1991. The Birds of Pakistan. Oxford University Press, New York, pp. 728.

Robinson, R.A., G.M. Siriwardena and H.Q.P. Crick. 2005. Size and trends of the house sparrow Passer domesticus population in Great Britain. Ibis, (Lond. 1859).

Robinson, W.D., M.S. Bowlin, I. Bisson, J. ShamounBaranes, K. Thorup, R.H. Diehl, T.H. Kunz, S. Mabey and D.W. Winkler. 2010. Integrating concepts and technologies to advance the study of bird migration. Front. Ecol. Environ. 8:354-361.

Rogers, C.M., M.Remon,E.D.Ketterson, J. C. Wright. 2006. Intra abd inter competition in birds for changing climate conditions. Auk. 50:112-117.

Root, T. 1., J. T. Price, K. R. Hall, S. H. Schneider, C. Rosenweig and J. A. Pounds. 2003. Fingerprints of global warming on wild animals and plants. Nature. 421:57-60.

Salgado-Ortiz, J., P.P. Marra and R.J. Robertson. 2009. Breeding seasonality of the mangrove warbler (Dendroica petechia bryanti) from southern Mexico. Ornithol. Neotrop.20:255-263.

Salido, L., B. V. Purse, R. Marrs, D.E. Chamberlain and S. Shultz. 2012. Flexibility in phenology and habitat use act as buffers to long-term population declines in UK passerines. Ecography.35:604-613.

Scheuerlein, A. and E. Gwinner. 2002. Is food availability a circannual zeitgeber in tropical birds? A field experiment on stonechats in Tropical Africa. J. Biol. Rhyth. 17:171180.

Seavy, N.E.S.Quader.J. Alexander and C.J. Ralph. 2005. Generalized linear model and point count data; Statistical considertaion for the design and analysis of monitering studies.United States. Dept.Agric, Forest services. pp.744-752.

Khattak, S. M. and S.A. Khalil. 2015. Assessment of temperature and rainfall trends in Punjab province of Pakistan for the period 1961-2014. J. Himal. Earth Sci. 48:42-61.

Shaw, L.M., D. Chamberlain and M. Evans. 2008. The House Sparrow Passer domesticus in urban areas: reviewing a possible link between post-decline distribution and human socioeconomic status. J. Ornithol. 149:293-299.

Singh, R., D.N. Kour, F. Ahmad and D.N. Sahi. 2013. Roosting behaviour of house sparrow (Passer domesticus Linnaeus, 1758) in some urban and rural areas of Jammu Division, J \& K. Munis Entomol. Zool. 8:782-789.

Suzuki, S. and E. Akiyama. 2008. Evolutionary stability of first-order-information indirect reciprocity in sizable groups. Theor. Popul. Biol. 73:426-436.

Szabo, J.K., N. Khwaja, S.T. Garnett and S.H.M. Butchart. 2012. Global Patterns and Drivers of Avian Extinctions at the Species and Subspecies Level. PLoS One. 7: e47080.

Taber, R.D., A.N. Sheri and M.S. Ahmad, 1967. Notes on Birds of Lyallpur. J. Mammal. 1: 372-375.

Thomas, C. D., A. Cameron, R. E. Green, M. Bakkenes, L. J. Beaumont, Y. C. Collingham, B. F. N. Erasmus. Extinction risk from climate change. Lett. Nat. 427:145148.

Valladares, F., E. Gianoli and J.M. Gómez. 2007. Ecological limits to plant phenotypic plasticity. New Phytol. 176:749-763.

Vickers, M. C. Manicom and L. Schwarzkopf. 2011. Extending the cost-benefit model of thermoregulation: high-temperature environments. Am. Naturalist. 177:452-461.

Walther, G.R., E. Post, P. Convey, A. Menzel, C. Parmesan, T.J.C. Beebee, J.-M. Fromentin, O. Hoegh-Guldberg and F. Bairlein. 2002. Ecological responses to recent climate change. Nature. 416:389-395.

Wright, J., R.E. Stone and N. Brown. 2003. Communal roosts as structured information centres in the raven, Corvus corax. J. Anim. Ecol. 72:1003-1014.

Yoder, J.M. 2004. The cost of dispersal: predation as a function of movement and site familiarity in ruffed grouse. Behav. Ecol. 15:469-476. 